\title{
Circulatory and Respiratory Changes Induced by Stimulation of the Thalamic Nuclei
}

\author{
Hideo UEDA, M.D., * Soichi KATAYAMA, M.D., \\ Hitoshi GOTO, M.D., and Kiyoshi ITO, M.D.
}

The purpose of this paper is to elucidate and to discuss the central regulation of circulatory and respiratory functions in the thalamus by electrical stimulation. The stimulation of the medial part of the thalamus-the midline, medial and anterior nuclei group-resulted in marked changes in blood pressure, cardiac beat, breathing and other visceral functions. But on stimulation of the ventral and lateral nuclei group, there occurred little or no change in the vegetative activities. These findings are well correlated with the information about the anatomical connections of thalamic nuclei. Therefore, this medial portion seems to represent the autonomic area in the thalamus.

$\mathrm{T}$ HE thalamus is a relay station of the sensory system in the forebrain and is also responsible for the mechanisms of movement, emotion and consciousness. From the anatomical point of view, the thalamus was proved to have fiber connections with cortical and subcortical areas and the emphasis should be given to its connection with the hypothalamus, frontal cortex and limbic structures. Therefore, one might easily assume the participation of the thalamic nuclei in the vegetative functions.

Since the works of Karplus and Kreidl (1909-1927), most of the previous studies on the autonomic function of diencephalon focussed their interests mainly on the hypothalamus except the classic study of Sachs ${ }^{11}$ (1911) on the thalamus.

However, first performance of thalamotomy by Spiegel in 1947 stimulated further experiments on the autonomic functions of the thalamus. Among them, Akert et al. ${ }^{2)}$ (1951), Baird et al. ${ }^{3)}$ (1952), Dell et al. ${ }^{4)}$ (1952), Misao et al. ${ }^{5)}$ (1954), Masaki ${ }^{6}$ (1955), and Monnier ${ }^{7)}$ (1955) have been known. In these works there have been some confusions in the classification or nomenclature of the thalamic nuclei and some authors even did not clearly describe the sites stimulated. Therefore, the autonomic function of each thalamic nucleus remains to be thoroughly examined. For this reason, the authors made the following experiments.

From the Second Department of Internal Medicine, Faculty of Medicine, University of Tokyo, Tokyo

* Professor of Internal Medicine 


\section{Materials and Methods}

Twenty-five dogs were used in present experiments. Morphine chloride $(6 \mathrm{mg} . \mathrm{Kg}$.), or the combination of morphine chloride $(3 \mathrm{mg} . / \mathrm{Kg}$.) with chloralose $(50-70 \mathrm{mg}$. $/ \mathrm{Kg}$.) were used for the anesthesia. By using the stereotaxic instrument, devised by the Institute of Brain Research, Faculty of Medicine, University of Tokyo, the stimulation electrode was placed. The location of the tip of this electrode was determined by histological control following each experiment. For precise localization of the stimulus, a bipolar concentric electrode was used and this electrode was completely insulated except for the tip.

The electrical stimuli were rectangular voltage pulses; their duration was 1 msec.; their voltage 1 to 6 volts (4 to 30 volts in crest value); and their frequency 100 cycles per second. Each stimulus was applied for approximately 30 seconds.

The blood pressure was recorded on a kymograph by means of a mercury manometer connected to the femoral artery. Electrocardiogram was taken on the standard leads I and III and the intraatrial lead. The effect of the myogram induced by convulsion was sometimes seen on thalamic stimulation which could interfere the EKG tracing. For this reason, an electrode was inserted into right atrial cavity in order to eliminate the myogram and to obtain a tall and clear cut picture of $\mathrm{P}$-wave.

The respiratory movement of the thorax was registered on a kymograph by means of a tambour connected to the cuff wrapping around the thorax, and simultaneous recording was made with an ink-writing oscillograph using a transducer of rubber tube filled with zinc sulfate solution.

In this paper the nuclei of the thalamus are classified into five groups, namely the anterior nuclei, the nuclei of the midline, the medial nuclei, the ventral nuclei and the lateral nuclei group, according to the morphological studies on the diencephalon of carnivora by Rioch ${ }^{8)}$ (1936).

The intralaminar nuclei group is included in the medial nuclei group, and the following structures adjacent to the thalamus are excluded; the epithalamus, the subthalamus, the medial geniculate body and the lateral geniculate body.

\section{RESUlts}

Sixty one different points in five nuclei groups of the thalamus were stimulated.

Circulatory and respiratory responses as well as other visceral and somatic changes obtained by this stimulation are shown in Table I to Table V. The results can best be stated by taking up each nucleus separately. Fig. 1 and 2 show degrees or types of responses and the stimulated sites in 7 diagrams of the frontal section of the thalamus.

Circulatory Responses -

Changes in blood pressure: In most experiments, changes elicited were pressor effects. Depressor effects were seen in a few points of the medial, ventral and lateral nuclei group. In Fig. 4 blood pressure changes are expressed as a ratio to the control level, and their degrees are divided into 4 stages. In- 
Table I. Responses to Stimulation of the Anterior Nuclei Group

\begin{tabular}{c|c|c|c|c|c}
\hline Stimulated site & $\begin{array}{c}\text { No. of } \\
\text { exp. }\end{array}$ & $\begin{array}{c}\text { Blood } \\
\text { pressure }\end{array}$ & Heart beat & Respiration & $\begin{array}{c}\text { Other visceral \& } \\
\text { somatic changes }\end{array}$ \\
\hline N. anterodorsalis & 5 & $H$ & $\begin{array}{r}\text { S-T, } \mathrm{T}_{1}, \mathrm{~T}_{2} \\
\text { V.Es-B, Bl }\end{array}$ & None \\
\hline N. anteroventralis & 5 & H H & A.Es & - & $\begin{array}{c}\text { Mydriasis(1), Convul- } \\
\text { sion(I), Incontinence(1) }\end{array}$ \\
\hline N. anteromedialis & 2 & 0 & 0 & None \\
\hline
\end{tabular}

Note:

1) Blood pressure responses are expressed as follows:

- Fall

o Little or no elevation ( $0 \sim 20 \%$ increase to control level)

+ Slight elevation $\quad(21 \sim 40 \%)$

\# Moderate elevation (41 80\%)

II Marked elevation (over $81 \%$ )

2) Changes in cardiac rhythm are shown in abbreviation as follows:

S-T $T_{1}$ Marked sinus tachycardia (over $100 \%$ increase to basal rate)

S-T $\mathrm{T}_{2}$ Moderate sinus tachycardia

S-B Sinus bradycardia

V.Es-A Ventricular extrasystole with shorter coupling period

V.Es-B Ventricular extrasystole with longer coupling period

V-T Ventricular tachycardia

N Nodal ectopic beat

A.Es Auricular extrasystole

Bl Atrio-ventricular block

3) Patterns of respiratory change are divided according to the change of its frequency and amplitude.

\begin{tabular}{|c|c|c|c|}
\hline $\begin{array}{l}\text { Freq. } \\
\text { Amp. }\end{array}$ & $\uparrow$ & 0 & $-\downarrow$ \\
\hline$\uparrow$ & + & + & + \\
\hline 0 & + & 0 & - \\
\hline$\downarrow$ & + & - & - \\
\hline
\end{tabular}

$+:$ Acceleration

$0:$ No change

- : Inhibition

4) The number in ( ) indicates the incidence of each sign,

crease of less than $20 \%$ is often followed by a gasping respiration and it is considered to have little significance. Increase of 21 to $40 \%$ indicates slight elevation, 41 to $80 \%$ moderate and over $81 \%$ marked.

As seen in Fig. 4, the midline and medial nuclei group stimulation yields the most prominent increase in blood pressure. Both groups show moderate to marked elevation in about two-thirds of the experiments and their threshold for the stimuli is low and even 1 to 2 volts elicited marked elevation of blood pressure. On midline nuclei stimulation, all experiments but one, showed blood pressure elevation with relatively strong stimuli (4 to 6 volts), but on the medial nuclei stimulation of same intensity caused little or no changes in 10 cases. The ventral and lateral nuclei were not clearly 
Table II. Responses to Stimulation of the Midline Nuclei Group

\begin{tabular}{|c|c|c|c|c|c|}
\hline Stimulated site & $\begin{array}{l}\text { No. of } \\
\text { exp. }\end{array}$ & $\begin{array}{c}\text { Blood } \\
\text { pressure }\end{array}$ & Heart beat & Respiration & $\begin{array}{l}\text { Other visceral \& } \\
\text { somatic changes }\end{array}$ \\
\hline $\begin{array}{l}\text { N. commissuralis } \\
\text { interparataenialis }\end{array}$ & 1 & biphasic & $\mathrm{S}-\mathrm{T}_{2}$ & 0 & None \\
\hline N. rhomboidalis & 7 & $H \sim H$ & $\begin{array}{c}\mathrm{S}-\mathrm{T}_{2} \\
\text { V.Es-A, N }\end{array}$ & $+\sim-$ & $\begin{array}{l}\text { Mydriasis (3), Urin- } \\
\text { ary incontinence (1) }\end{array}$ \\
\hline $\begin{array}{l}\text { N. centralis medialis } \\
\text { (N. reuniens) }\end{array}$ & 8 & $+\sim H$ & $\mathrm{~S}-\mathrm{T}_{1}$, A.Es & $\begin{array}{c}+ \\
\text { Apneusis }\end{array}$ & $\begin{array}{l}\text { Mydr. (5), Piloerection } \\
\text { (3), Incontinence (3), } \\
\text { Convulsion (8) }\end{array}$ \\
\hline $\begin{array}{l}\text { N. commissuralis } \\
\text { interventralis }\end{array}$ & 6 & $H \sim \#$ & $\begin{array}{l}\mathrm{S}-\mathrm{T}_{2}, \mathrm{~A} . \mathrm{Es} \\
\mathrm{Bl}, \mathrm{V} . \mathrm{Es}-\mathrm{A}\end{array}$ & + & Convulsion (1) \\
\hline $\begin{array}{l}\text { N. paraventricularis } \\
\text { anterior }\end{array}$ & 7 & $H \sim H$ & $\begin{array}{l}\mathrm{S}-\mathrm{T}_{1}, \mathrm{~T}_{2} \\
\text { V.Es-A,B }\end{array}$ & $0 \sim+$ & $\begin{array}{l}\text { Mydriasis (5) } \\
\text { Convulsion (3) }\end{array}$ \\
\hline $\begin{array}{l}\text { N. paraventricularis } \\
\text { posterior }\end{array}$ & 2 & 世 & $\begin{array}{c}\mathrm{S}-\mathrm{T}_{2}, \mathrm{~V}-\mathrm{T} \\
\mathrm{V} . \mathrm{Es}-\mathrm{B}\end{array}$ & $\begin{array}{c}+ \\
\text { Apneusis }\end{array}$ & Mydriasis (2) \\
\hline Periventricular system & 8 & 世 & $\begin{array}{l}\mathrm{S}-\mathrm{T}_{1}, \mathrm{~T}_{2} \\
\text { A.Es, Bl }\end{array}$ & $+\sim-$ & $\begin{array}{l}\text { Mydriasis (7) } \\
\text { Convulsion (7) } \\
\text { Piloerection (1) }\end{array}$ \\
\hline
\end{tabular}

Table III. Responses to Stimulation of the Medial and Intralaminar Nuclei Group

\begin{tabular}{|c|c|c|c|c|c|}
\hline Stimulated site & $\begin{array}{l}\text { No. of } \\
\text { exp. }\end{array}$ & $\begin{array}{l}\text { Blood } \\
\text { pressure }\end{array}$ & Heart beat & Respiration & $\begin{array}{l}\text { Other visceral \& } \\
\text { somatic changes }\end{array}$ \\
\hline N. parataenialis & 5 & $H$ & $\begin{array}{c}\mathrm{S}-\mathrm{T}_{1}, \mathrm{~T}_{2} \\
\text { V.Es-A, A.Es }\end{array}$ & $-\sim+$ & $\begin{array}{l}\text { Mydriasis (3) } \\
\text { Convulsion (1) }\end{array}$ \\
\hline N. medialis dorsalis & 14 & $0 \sim H$ & $\begin{array}{r}0 \sim S-T_{1}, T_{2} \\
N \\
\text { V.Es }-A, B, B l\end{array}$ & $\begin{array}{l}0 \sim+ \\
\text { Apneusis }\end{array}$ & $\begin{array}{l}\text { Mydriasis (3) } \\
\text { Convulsion (3) }\end{array}$ \\
\hline N. submedius & 4 & $+\sim H$ & $\begin{array}{l}\mathrm{S}-\mathrm{T}_{2} \\
\text { A.E. }\end{array}$ & + & $\begin{array}{l}\text { Urinary } \\
\text { incontinence (1) }\end{array}$ \\
\hline $\begin{array}{l}\text { N. tractus habenulo- } \\
\text { peduncularis }\end{array}$ & 3 & $H \sim H$ & $\begin{array}{c}\mathrm{S}-\mathrm{T}_{2} \\
\text { V.ES-A }\end{array}$ & + & None \\
\hline N. parafascicularis & 4 & $H \sim H$ & V.Es-B, Bl & $\begin{array}{c}\text { Apneusis } \\
+\end{array}$ & $\begin{array}{l}\text { Mydr. (4), Convul. (3) } \\
\text { Urin. incont. (2) }\end{array}$ \\
\hline N. paracentralis & 14 & $+\sim H$ & $\begin{array}{l}0 \sim \mathrm{S}-\mathrm{T}_{1} \\
\mathrm{~V} . \mathrm{Es}-\mathrm{B}\end{array}$ & $\sim \sim+$ & $\begin{array}{l}\text { Convulsion (2) } \\
\text { Urin. incont. (1) }\end{array}$ \\
\hline Centre médian & 6 & H & $\begin{array}{l}\mathrm{S}-\mathrm{T}_{1}, \mathrm{~T}_{2} \\
\mathrm{~V}, \mathrm{Es}-\mathrm{B}\end{array}$ & $\stackrel{+}{+}$ & $\begin{array}{l}\text { Convulsion (6) } \\
\text { Piloerection (3) } \\
\text { Mydriasis (5) }\end{array}$ \\
\hline N. centralis lateralis & 4 & $-\sim 0$ & $0 \sim \mathrm{S}-\mathrm{T}_{1}$ & $0 \sim-$ & None \\
\hline
\end{tabular}

responsive. Patterns of blood pressure elevation were variable, but most of them showed abrupt increase to the near maximal level instantaneously with stimulation, and continued to rise slowly during stimulation, and at the end of the stimulation they greatly decreased in thcir magnitude and then gradually 
Table IV. Responses to Stimulation of the Ventral Nuclei Group

\begin{tabular}{|c|c|c|c|c|c|}
\hline Stimulated site & $\begin{array}{l}\text { No. of } \\
\text { exp. }\end{array}$ & $\begin{array}{c}\text { Blood } \\
\text { pressure }\end{array}$ & Heart beat & Respiration & $\begin{array}{l}\text { Other visceral \& } \\
\text { somatic changes }\end{array}$ \\
\hline $\begin{array}{l}\text { N. ventralis, } \\
\text { pars anterior }\end{array}$ & 6 & $\underset{\sim+}{\sim+}$ & $0 \sim S-T_{2}$ & $0 \sim+$ & $\begin{array}{l}\text { Mydriasis } \\
\text { Convulsion }\end{array}$ \\
\hline $\begin{array}{l}\text { N. ventralis, } \\
\text { pars medialis }\end{array}$ & 3 & + & $\mathrm{S}-\mathrm{T}_{2}$ & $-\sim+$ & None \\
\hline $\begin{array}{l}\text { N. ventralis, } \\
\text { pars externa }\end{array}$ & 5 & $0 \sim H$ & $S-T_{1}, T_{2}$ & $-\sim+$ & $\begin{array}{l}\text { Mydriasis } \\
\text { Convulsion }\end{array}$ \\
\hline $\begin{array}{l}\text { N. ventralis, } \\
\text { pars arcuata }\end{array}$ & 4 & + & $S-T_{1}$ & + & $\begin{array}{l}\text { Mydriasis } \\
\text { Convulsion }\end{array}$ \\
\hline
\end{tabular}

Table V. Responses to Stimulation of the Lateral Nuclei Group

\begin{tabular}{l|c|c|c|c|c}
\hline \multicolumn{1}{|c|}{ Stimulated site } & $\begin{array}{c}\text { No. of } \\
\text { exp. }\end{array}$ & $\begin{array}{c}\text { Blood } \\
\text { pressure }\end{array}$ & Heart beat & Respiration & $\begin{array}{c}\text { Other visceral \& } \\
\text { somatic changes }\end{array}$ \\
\hline $\begin{array}{l}\text { N. lateralis, } \\
\text { pars anterior }\end{array}$ & 2 & 0 & 0 & $0 \sim-$ & None \\
\hline $\begin{array}{l}\text { N. lateralis, } \\
\text { pars intermedia }\end{array}$ & 2 & 0 & 0 & $0 \sim-$ & None \\
\hline $\begin{array}{l}\text { N. lateralis, } \\
\text { pars posterior }\end{array}$ & 6 & $-\sim+$ & A.Es & $-\sim+$ & $\begin{array}{l}\text { Convulsion (1) } \\
\text { Mydriasis (3) }\end{array}$ \\
\hline N. reticularis & 2 & $+\sim+$ & $\begin{array}{c}\text { S-T } \\
\text { N }\end{array}$ & - & $\begin{array}{l}\text { Convulsion (2) } \\
\text { Mydriasis (1) }\end{array}$ \\
\hline
\end{tabular}

returned to the basal level. In a few cases, however, after cessation of the stimulation the blood pressure decreased to the basal level but ascended again with clonic convulsion.

Changes in cardiac beat: Acceleration of cardiac rate was observed in most of the cases, and cardiac inhibition was rarely encountered on thalamic stimulation. Fig. 5 shows changes in heart rate yielded on each thalamic nucleus stimulation. It is expressed as a ratio (\%) of the heart rates for each 10 seconds before and during stimulation. In 18 out of 39 cases of midline nuclei stimulation and in 8 out of 31 cases of medial nuclei stimulation, there appeared marked tachycardia indicating over $100 \%$ increase of the basal rate. On the stimulation of other nuclei groups, cardiac acceleration was in a lesser degree. In $6 \%$ of all experiments performed upon some regions of the anterior, medial and lateral nuclei, mild cardio-inhibitory responses were obtained.

Various arrhythmias such as supraventricular and ventricular extrasystole or escape and atrio-ventricular block etc. were also observed. Ucda et al. ${ }^{9)}$ (1959) reported that ventricular arrhythmias induced on electrical stimulation of the brain stem might be divided into two types (" $A$ " and " $B$ ") according to their EKG features and modes of appearance. On thalamic 

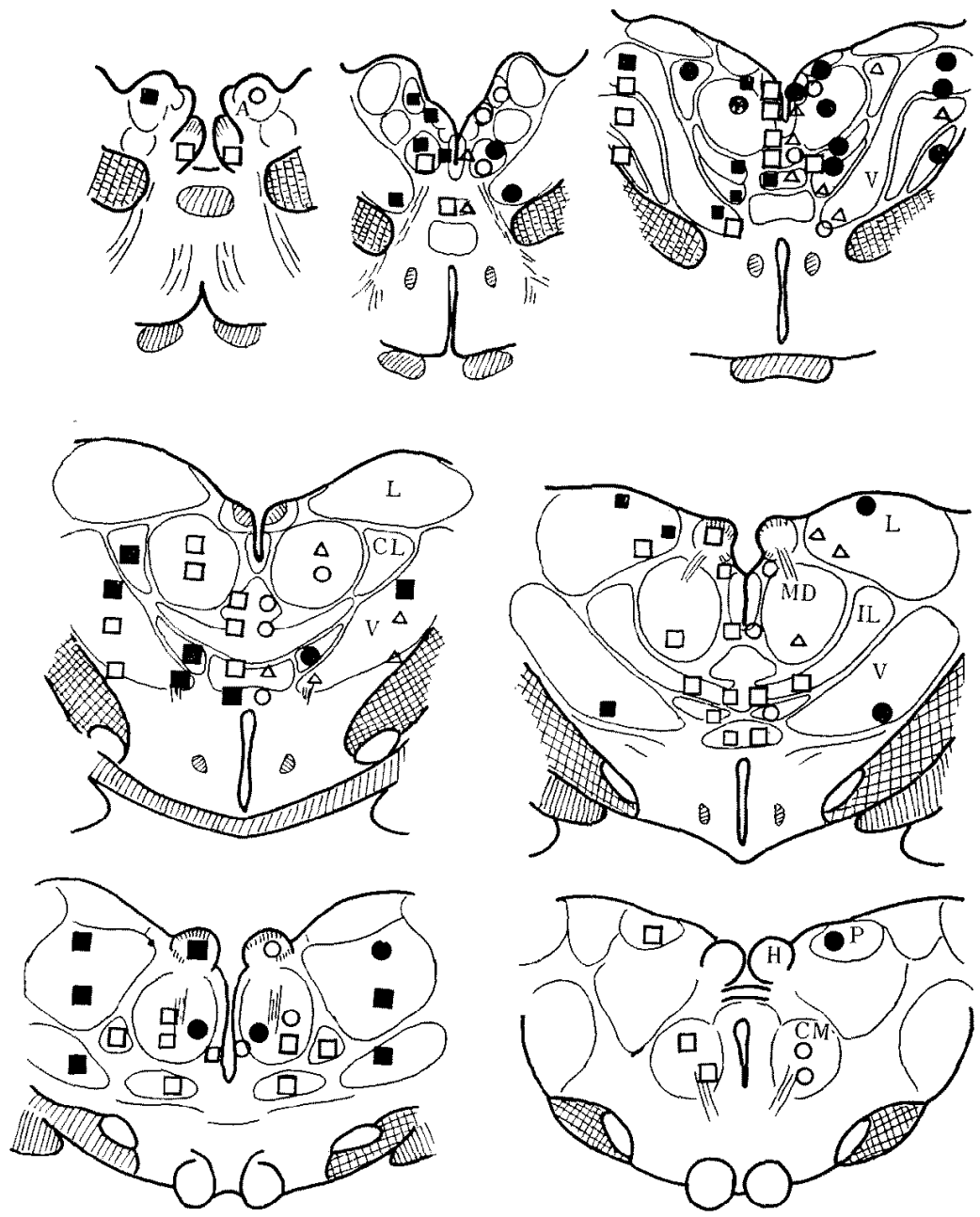

Fig. 1. Mappings of the stimulated sites at which vasomotor and respiratory effects were obtaincd. Vasomotor effects on the right side of each diagram, respiratory effects on the left side. Symbols are as follows.

A: N. anterior

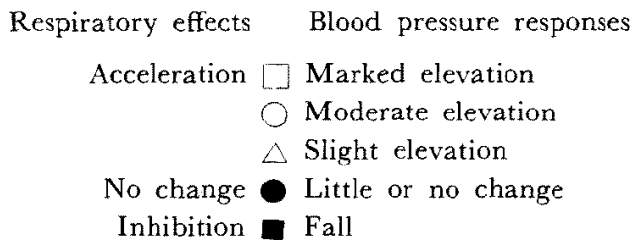

CL: N. centralis lateralis

CM: Centre médian

H: Habenula

IL: Intralaminar nuclei

L: N. lateralis

MD: N. medialis dorsalis

P: Pulvinar

V: N. ventralis

stimulation both type $\mathrm{A}$ and $\mathrm{B}$ were found. Type $\mathrm{A}$, with shorter coupling period (usually $0.20-0.30 \mathrm{sec}$.), frequently appears in the early period of stimulation and tends to appear in the inspiratory phase independently of blood pressure elevation. This type of extrasystole was elicited on stimulation 

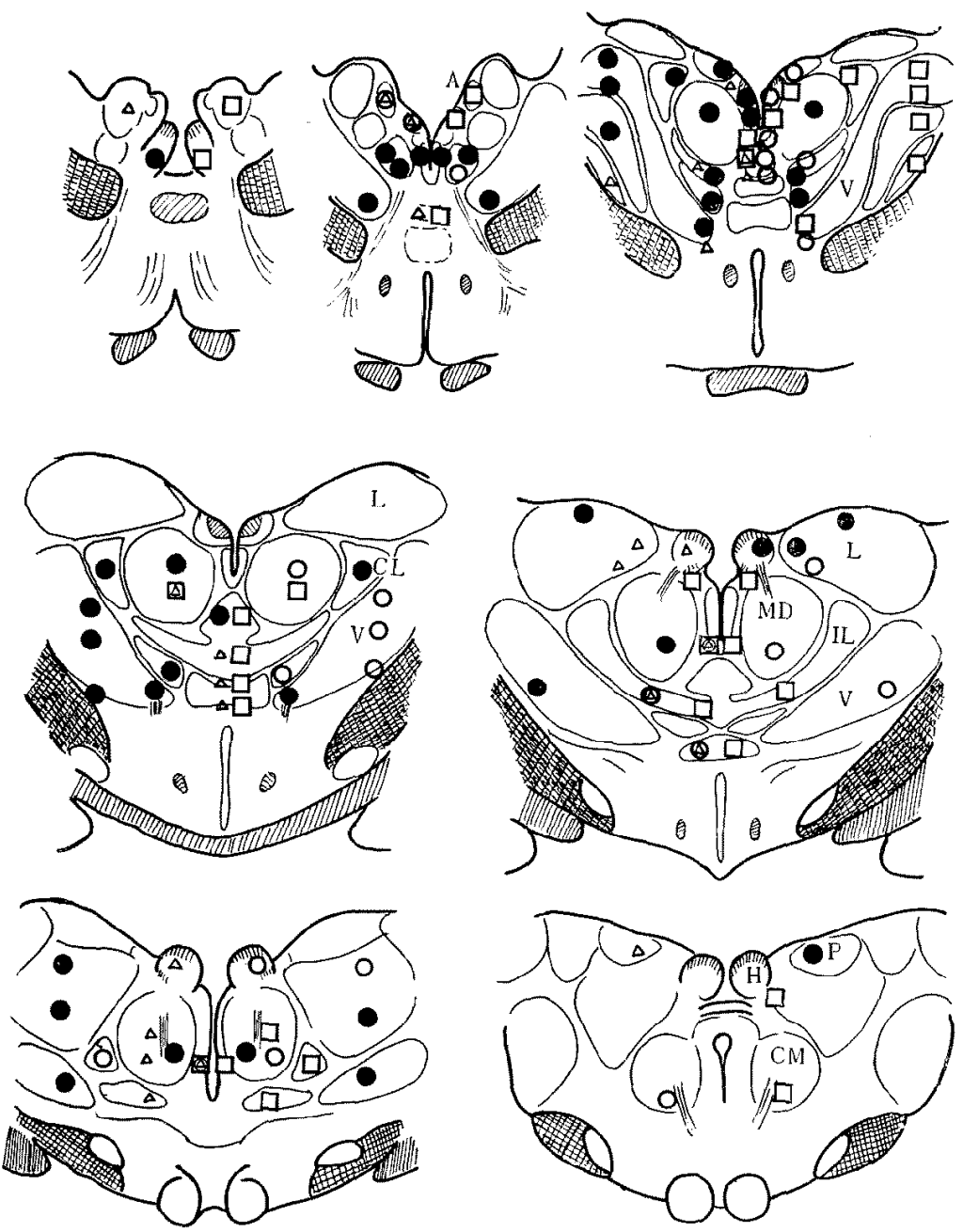

Fig. 2. Mappings of the stimulated sites at which changes in heart beats were obtained. Changes in heart rate on the right side of each diagram, types of arrhythmia on the left side. Symbols are as follows.

A: N. anterior
Types of arrhythmia Changes in heart rate
CL: N. centralis lateralis
V.Es-A $\square \mathrm{S}-\mathrm{T}_{1}$
V.Es-B $\bigcirc \mathrm{S}-\mathrm{T}_{2}$
Others $\triangle$
Not elicited No change
a $\mathrm{S}-\mathrm{B}$
CM: Centre médian
H: Habenula
IL: Intralaminar nuclei
L: N. lateralis
MD: N. medialis dorsalis
P: Pulvinar
$\mathrm{V}: \mathrm{N}$. ventralis

of the medial portion in the brain stem in general, and in the thalamus it occurred only on stimulation of the nuclei of midline and medial nuclei group. Type " B" extrasystole with longer coupling period (usually more than 0.30 sec.), simulating escaped beat because of its occurrence with prolongation of 


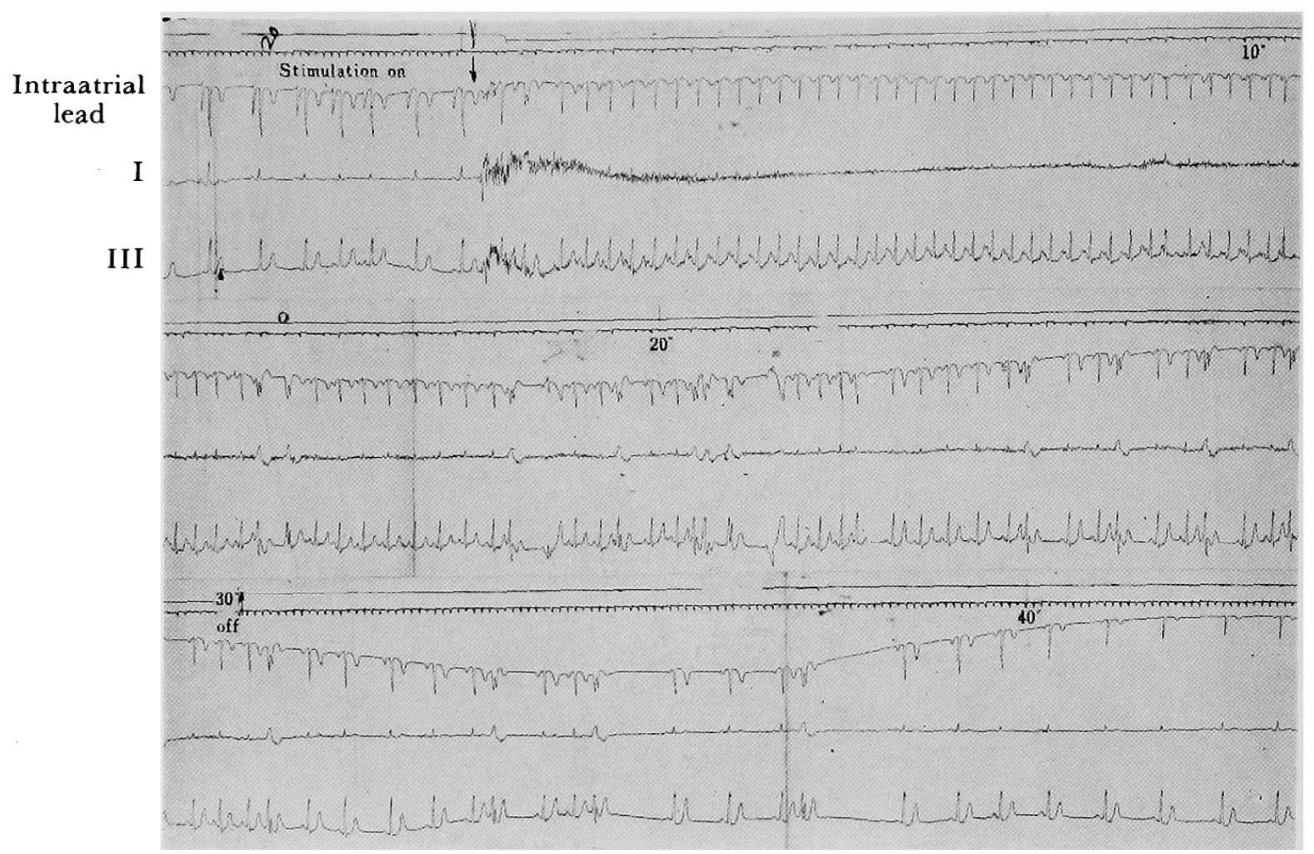

A

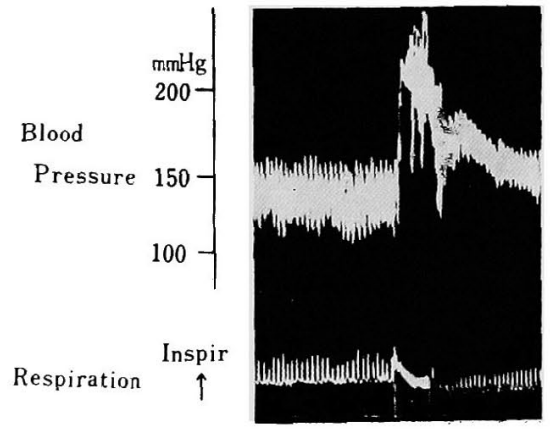

B

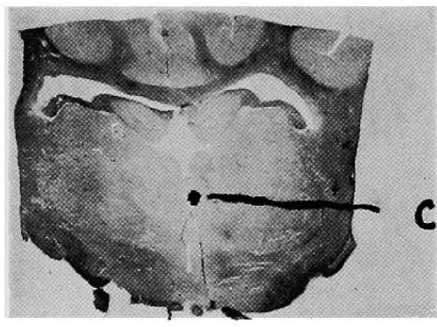

C

Fig. 3. Records of stimulation on midline nuclei (Dog No. 19, Exp. 20).

A: Electrocardiographic tracings taken on intraatrial lead and standard lead I and III.

B: Kymographic records of blood pressure and respiratory responses.

C: Frontal section of thalamus indicating the site of stimulation (C: Nucl. paraventricularis anterior).

$\mathrm{P}-\mathrm{P}$ and/or P-R interval, occurred when a relatively widespread region of the brain stem was stimulated. In the thalamus, it also was observed on stimulation of the anterior nuclei besides the above mentioned two nuclei groups. On stimulation of the ventral and lateral nuclei groups, few arrhythmias were yielded.

\section{Respiratory Responses-}

Changes in respiration are classified in the notes given under Table I. Besides them apneusis was also included. The results are shown in Table I 


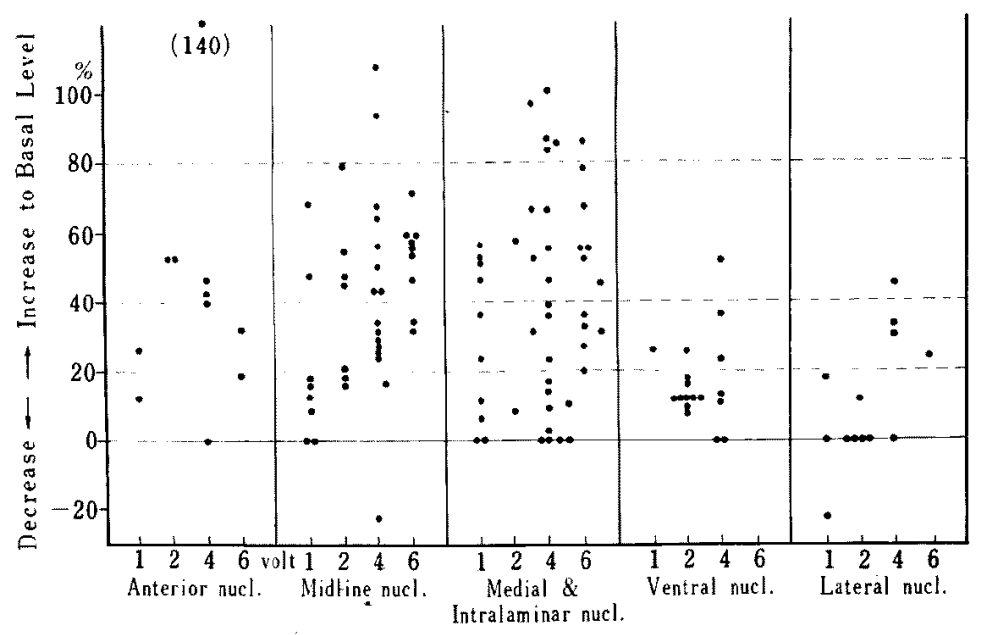

Fig. 4. Blood pressure responses after stimulation of different thalamic nuclei.

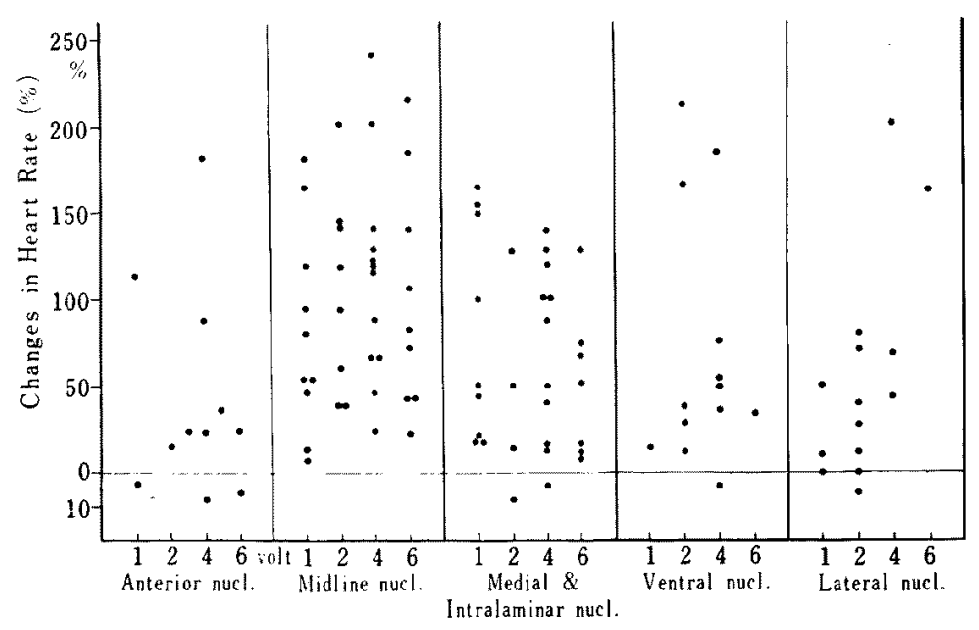

Fig. 5. Changes in heart rate after stimulation of different thalamic nuclei.

to $\mathrm{V}$, and on the left side of each diagram in Fig. 1.

On stimulation, the midline and medial nuclei yielded mainly facilitatory responses but in a few cases respiratory inhibition was also found on stimulation of nuclei such as nucl. rhomboidalis, periventricular system, nucl. parataenialis and nucl. centralis lateralis. From the ventral nuclei there occurred both facilitatory and inhibitory responses, and from most of the lateral nuclei, inhibitory ones. In all cases of anterior nuclei stimulation, there appeared a marked inhibition of respiration.

Inspiratory apnea due to tonic convulsion was seen in some experiments, and the respiratory patterns in these cases are difficult to be decided whether facilitatory or inhibitory. 


\section{Other Visceral and Somatic Signs-}

Besides circulatory and respiratory responses, visceral signs such as pupillary change, exophthalmos, incontinence of urine or feces and piloerection were observed. Pupillary change, in most cases mydriasis, and exophthalmos were yielded from any thalamic nuclei stimulation, but piloerection, though infrequent on thalamic stimulation, was localized only to midline and medial nuclei stimulation. From anterior nuclei other than these two, urination and defecation was yielded.

As to somatic signs, tonic convulsion occurred in some cases of midline, medial and anterior nuclei stimulation, but less in other nuclei groups. By stimulating nucl. ventralis pars arcuata, centre médian, nucl. medialis dorsalis, nucl. paracentralis and nucl. paraventricularis anterior, a clonic convulsion was observed following tonic convulsion before or after the end of stimulus.

Various Responses with the Change of Stimulation Parameter-

Intensity of stimulus: The threshold to stimuli was variable because of different excitability in each nucleus. Fig. 6 shows how blood pressure response varies when the intensities of stimulus are modified in two cases of different threshold. As to the change in heart rate, the same tendency was noted (Fig. 7). Generally spcaking, in the midline and medial nuclei group the threshold was low (see Fig. 4 and 5).
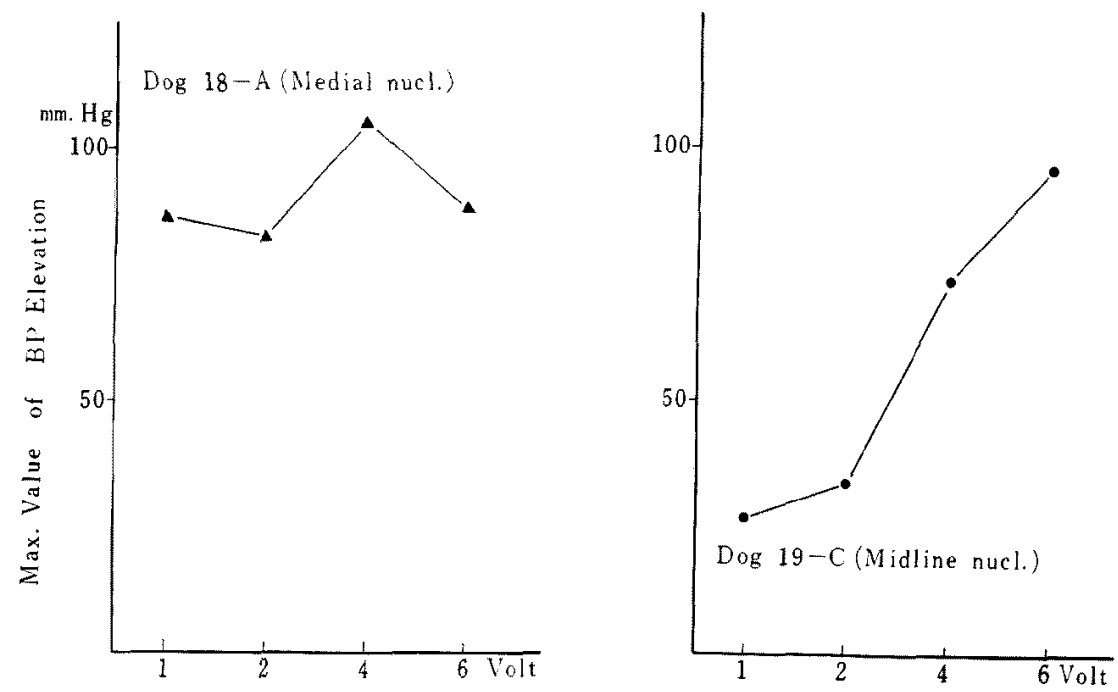

Fig. 6. Blood pressure responses to electrical stimulation of various intensities.

Frequency of stimulus: The kymographic records seen in Fig. 8 show remarkable changes in blood pressure and respiratory response to various frequencies of stimulus (other parameters remained constant). In this case, the adequate frequency lies between 60 to 100 cycles per second. In our experiment, relatively high frequency, chiefly $100 \mathrm{c} / \mathrm{s}$, was used throughout 

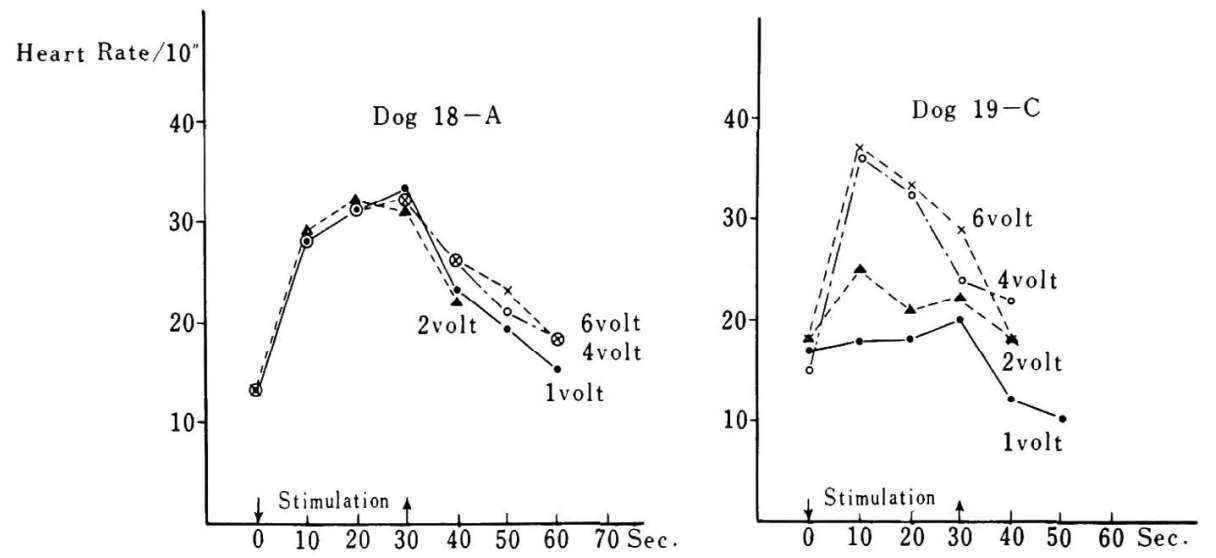

Fig. 7. Changes in heart rate on various intensity stimulation.

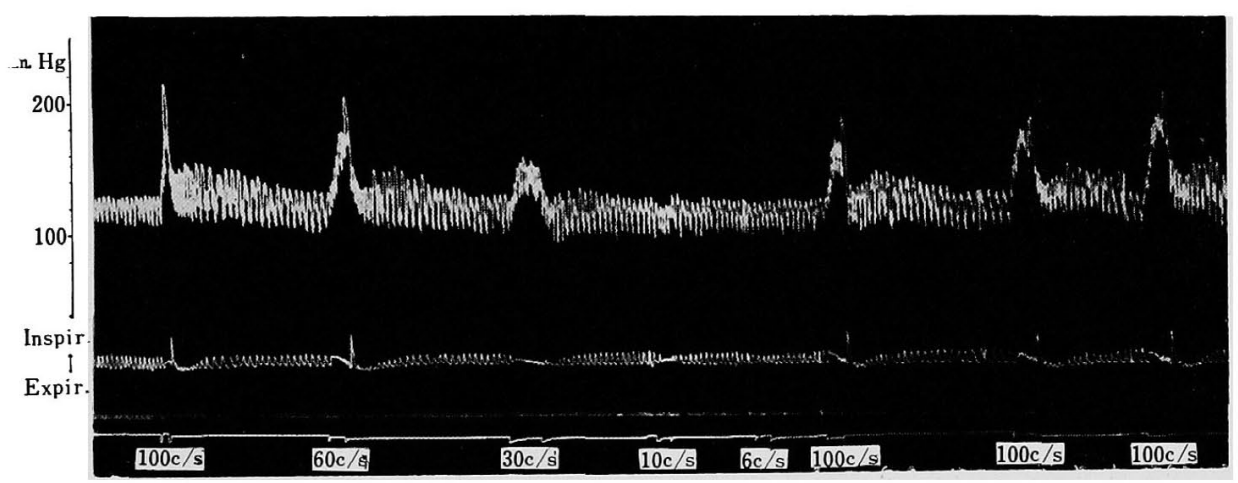

Fig. 8. Blood pressure and respiratory responses to various frequency stimulation of thalamic nuclei (midline nucl.).

the study, and this might be a cause of rare incidence of depressor effect.

\section{Discussion}

The participation of the thalamus in the autonomic functions is inferred on the following grounds.

a) Clinical; "thalamic syndrome" involves the various autonomic signs and symptoms as reported by Vincent (1908), Bechterew, Schüster ${ }^{10)}$ (1936), van Bogaert ${ }^{11)}$ (1949) and Okinaka et al. ${ }^{12)}$ (1953) etc.

b) Neuroanatomical ; the thalamus has fiber connections with the "visceral brain " as demonstrated by the retrograde degeneration method and physiological neuronography. The details will be referred to, in the following pages.

c) Physiological; the stimulation or destruction of the thalamic nuclei in animals may cause changes in autonomic functions. This is the very problem with which the authors dealt in this paper.

Since Danilewsky (1875) claimed that certain regions of the thalamus 
were concerned with changes in blood pressure and pulse rate, a number of other observers have directed their investigations towards this subject. Sachs ${ }^{11}$ (1911) was the first one who attempted to clarify their localizations. He noticed the elevation of blood pressure and changes in respiration by stimulating the various portions of the thalamus, but he ascribed these phenomena to the excitation of afferent nerve fibers of thalamic nuclei and said "there is no necessity for invoking the existence of special centers." In his paper the portions inert to stimulation were the median nuclei and the upper anterior end of the lateral thalamus. Since this work, almost no investigation of the thalamic autonomic functions was carried out.

However in reccnt years, Akert et al. ${ }^{21}$ (1951) observed forced respiration by electrical stimulation of the anterior portion of the thalamus in unanesthetized cats. Baird et al. ${ }^{3 \prime}$ (1952) reported that electrical stimulation of the anterior nuclei of the anesthetized cats and human revealed respiratory inhibition and mostly depressor effects on blood pressure. As for the changes in breathing, Dell et al.4) (1954) showed that stimulation of nucl. ventralis anterior yielded a slowing down of respiration rate, and occasional apnea in some cases. In Japan, Misao \& others ${ }^{5)}$ (1954) investigated the effects on peripheral blood picture, electrocardiogram and electrocorticogram by electrolytical destruction of the subcortical area, but failed to elicit electrocardiographic changes from the posterior nuclei. Masaki ${ }^{6)}$ (1955) stimulated the anterior nuclei and the medial region of the posterior thalamus chemically and observed blood pressure elevation, respiratory inhibition and other vegetative signs such as mydriasis, salivation and piloerection. Monnier ${ }^{7)}$ (1955) reported a case of electrical stimulation of the human thalamus and observed hyperpnea, tachycardia and thirst from the "région médiane" which consisted chiefly of intralaminar structure and was surrounded by " $\mathrm{n}$. ventro-postéromédiane," " $n$. dorso-médiane" and "centre médian." He correlated this phenomena with hypothalamo-thalamic connection. Korteweg' ${ }^{13)}$ (1957) described the electrocardiographic changes on subcortical stimulation. In his study, an electrical stimulation of the thalamus, though its localization was undetermined, caused no disturbances in cardiac rhythm but showed blood pressure response at a minimum level and a slight change in the $T$-wave. The respiratory acceleration was also noted. From the review of previous literatures, apparently no extensive and systematic investigations of thalamic autonomic functions have been carried out. In this regard, the present study was done and an attempt was made to discuss the results with special reference to anatomical connections between thalamic nuclei and the "visceral brain."

Anterior Nuclei Group-(Table I, Fig. 1 and 2)

This nuclei group consists of anterodorsal, anteroventral and anteromedial elements. Pressor effect of this nuclei was reported in the papers of Sachs and Masaki respectively, but Baird declared that depressor effect was the rule. Our opinion is in accordance with that of the former. We found the respiratory responses were inhibitory in nature as in all previous studies. 


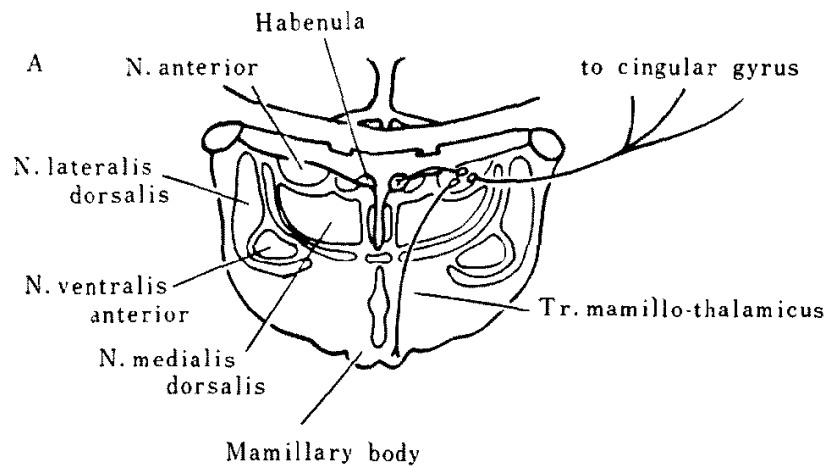

B

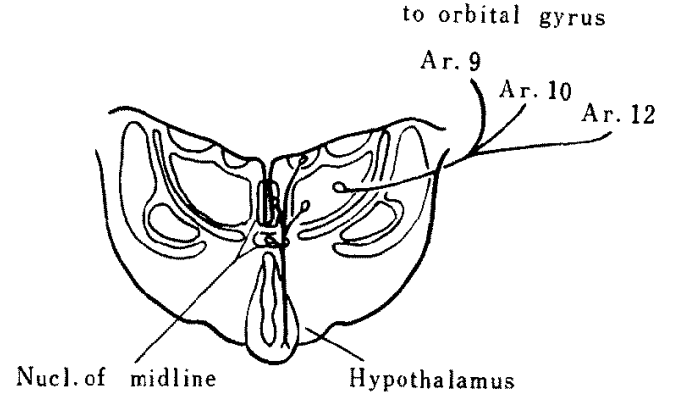

Fig. 9. Hypothalamo-thalamo-frontal connections (Modification of the figure of Hoff \& Osleri4).

In our experiment, acceleration in cardiac rate, arrhythmia of various types, mydriasis, urinary incontinence and convulsion were observed.

As seen in Fig. 9-A, the afferent impulses arising mainly from the homolateral mamillary body reaches the anterior thalamic nuclei via the mamillothalamic tract of Vicq D'Azyr. Changing the neuron at that site, the fibers project into specific cortical areas. The anteromedial element projects to the anterior part of the cingulate gyrus (Area 24) and perhaps to Area 32; the anteroventral element sends its fibers mainly to the posterior part of the cingulate gyrus (Area 23) and partly to Area 24; and the small anterodorsal element projects to the retrosplenial region (Area 29) of the cortex (Mitchelli5)). Area 24 is known to be a suppressor in nature and stimulation of this area produced alterations in the heart rate, blood pressure and respiration (Mitchell $\left.{ }^{15}\right)$. Since both mamillary body and cingulate gyrus have a connection with the other limbic system, Papez (cit. from Le Gros Clark ${ }^{16)}$ ) suggested the following anatomical circuit which may maintain a continuous cycle of functional relationship between the hypothalamus and neopallial cortex, that is;

hippocampus $\rightarrow$ fornix $\rightarrow$ mamillary body $\rightarrow$ anterior thalamic nucleus $\rightarrow$ cingulate gyrus (limbic cortex) $\rightarrow$ cingulum $\rightarrow$ hippocampus

Thus the anterior thalamic nucleus, member of this circuit, may be concerned with complicated integration of both autonomic and somatic systems in cortical and subcortical levels. 
Midline Nuclei Group-(Table II, Fig. I and 2)

This group consists of a number of nuclei occupying massa intermedia and periventricular grey matter, and is in contact with the hypothalamus particularly tuber cinereum through the periventricular fiber system (Gurdjian) which is mainly unmyelinated and lying close to the ependyma of the third ventricle $\left(\mathrm{Niimi}^{17)}\right)$.

Therefore this nuclci group must have some functional relation with the hypothalamus. We noticed the most striking responses on the stimulation of this group. In approximately $50 \%$ of the cases, moderate to marked rise of blood pressure, and marked acceleration of cardiac rate were seen. Various types of arrhythmia, including ventricular extrasystole of type A, and respiratory facilitation or apneusis were observed. Besides circulatory and respiratory changes, other visceral and somatic signs appeared. Fig. 3 shows the results of stimulation of the midline nuclei. The electrical stimulus of $100 \mathrm{c} / \mathrm{s}, 1 \mathrm{msec}$. in duration and 6 volts caused blood pressure elevation of $86 \mathrm{~mm} . \mathrm{Hg}$. This caused also rapid respiration, and disturbances in cardiac rhythm such as sinus tachycardia, supraventricular and ventricular extrasystoles with a short run or trigeminy. The nuclei of this group are small and poorly defined so that their responsiveness remains to be unnoticed by most of the investigators except Sachs who observed moderate to marked rise of blood pressure and inspiratory inhibition associated with forced inspiration, though the pulse rate did not change on the stimulation of nucl. reuniens. But he did not make any remarks about its significance.

Medial Nuclei Group and Intralaminar Nuclei Group-(Table III, Fig. 1 and 2)

In this experiment, these areas next to the midline nuclei group revealed marked visceral responses on stimulation. However, Sachs observed neither respiratory nor circulatory changes on the stimulation of nucl. medius. Accoring to Misao, there appeared no electrocardiographic change on medial nuclei stimulation. Only Monnier suggested the hypothalamo-thalamic correlations on the ground that stimulation of " région médiane " called forth respiratory and cardiac acceleration.

In these papers, the nomenclature of the nuclei is not always definite and it is difficult to compare them with our results.

The anatomical relations of the medial nuclei group to the hypothalamus or frontal cortex were clarified by the human or animal leucotomy and electrophysiological studies. The principal part of the medial (dorso-medial) nucleus, the pars parvicellularis, has widespread connections with the frontal cortex such as the orbital region (Area $I 1$ and 47), inferior and middle frontal gyri (Area 45, 46 and probably 6) and superior frontal gyrus (Area 8 ); and the pars magnocellularis of the medial nucleus sends fibers to Area 11 and 12 in the orbital region. The hypothalamus is linked with medial thalamic nuclei, particularly with its pars magnocellularis, through the periventricular system of fibers of the third ventricle, and the medial nuclei are essentially relay station for the onward transmission to the frontal cortex of 
impulses originating in the hypothalamus (Mitchell ${ }^{15)}$ ). Recently, Droogleever Fortuyn and others ${ }^{18)}$ (1959) found a strong fibcr connection from the rhinencephalic structures at the base of the telencephalon towards the parataenial and dorsomedial nucleus of the medial nuclei group.

It is therefore justifiable to assume that in regard to these hypothalamothalamo-cortical connections the medial nuclei are concerned with autonomic functions besides mental and emotional activities. This hypothesis is proved to be true in this experiment.

Ventral Nuclei Group-(Table IV, Fig. 1 and 2)

This group is relay nuclei of the sensory system to cortex. In this nuclei group we found slight changes in circulatory functions following stimulation, and respiratory responses were variable though their degree was minimum. Sachs stated, however, that the stimulation of nucl. lateralis ventralis yielded a moderate to marked pressor effect in two-thirds of all experiments. Respiratory inhibition was the rule. He mentioned these results were similar in every respect to those observed when an afferent nerve is stimulated, therefore he ascribed them to reflex effects. Dell observed inhibition of breathing, and Misao could not elicit any change in the cardiac beat on this nuclei stimulation.

Lateral Nuclei Group-(Table V, Fig. 1 and 2)

The function of this nuclei group is not clearly known, but is assumed to be association nuclei in thalamus. In the present experiment, circulatory changes were scarcely obtained and respiration was slightly suppressed. Our results, on the whole, agreed with that of Sachs.

The latter two nuclei groups were more inert to stimuli as regards the visceral functions than other nuclei groups. Apparently it is duc to the fact that they have no anatomical connections with the "visceral brain."

From the results shown above, the autonomic respresentation in the thalamus was demonstrated in the medial portion of the thalamus--the midline, medial and anterior nuclei group.

In the authors' opinion, these findings are well correlated with the information about the anatomical connections.

\section{SUMMARY}

Circulatory and respiratory function of the thalamus was studied in 25 dogs and the following results were obtained.

(1) Marked elevation of arterial blood pressurc was observed by the stimulation of the midline nuclei group and medial nuclei group. Stimulating the anterior nuclei group, slight vasopressor responses were found. But the stimulation of the ventral and lateral nuclei group caused little change in blood pressure.

(2) The standard and intraatrial lead of electrocardiogram showed marked acceleration of cardiac rate and various arrhythmias such as nodal extrasystole or escape and ventricular extrasystole etc. by the stimulation of 
the midline and medial nuclei group and some portions of the anterior nuclei group. These ventricular extrasystoles were divided into 2 groups according to their characteristics in EKG and the regions causing each of them were also discussed. The stimulation of the ventral and lateral nuclei group scarcely resulted in any disturbances of the cardiac rhythm.

(3) Acceleration of breathing was shown on the stimulation of the midline, medial and ventral nuclei group. All cases of the anterior nuclei stimulation elicited marked inhibition of respiration.

(4) Other visceral and somatic changes such as pupillodilatation, erection of hair, urinary or fecal incontinence and convulsion were observed upon the stimulation of various regions in the thalamus, but they occurred most prominently on the midline and medial nuclei stimulation.

From the data above-mentioned, it can be concluded that the stimulation of the medial part of the thalamus - midline and medial nuclei group-results in marked changes in circulation, respiration and other autonomic functions. Furthermore, considering the anatomical relationship between the thalamic nuclei and the higher autonomic centers, it seems that the autonomic representation in the thalmus locates in this portion.

\section{REFERENCES}

1. Sachs, E.: J. Exp. Med. 14: 408, 1911.

2. Akert, K. et al.: J. Physiol. 113 : 19 P, 1951.

3. Baird, H. W. et al.: Pflügers Arch. ges. Physiol. 255 : 58, 1952.

4. Dell, M. B. et al.: Rev. neurol. $90: 275,1954$.

5. Misao, T. et al.: No to Shinkei 6:67, 1954 (In Japanese).

6. Masaki, K.: Nihon Seirigaku Zasshi 17: 691, 1955 (In Japanese).

7. Monnier, M.: Rev. neurol. 93: 267, 1955.

8. Rioch, D. M. : J. Comp. Neurol. 53: 319, 1931.

9. Ueda, H. et al.: Japanese Circulation Journal 23: 488, 1959.

10. Schüster, P.: Arch. f. Psych. u. Nervenkh. 106: 201, 1936.

11. van Bogaert, L.: Rev. neurol. 83 : 18, 1950.

12. Okinaka, S. et al.: Physiological and Clinical Studies on the Diencephalon, edited by Ishibashi, T., (1st ed.), Igakushoin, Tokyo, p. 226, 1954 (In Japanese).

13. Korteweg, G. C. J. et al.: J. Neurophysiol. 20 : 100, 1957.

14. Hof, H. u. Osler, G.: Neurologie auf den Grundlagen der Physiologie, Verlag für med. Wissenschaften W. Maudrich, Wien, p. 172, 1957.

15. Mitchell, G. A. G.: Anatomy of the Autonomic Nervous System (1st ed.), E. \& S. Livingstone Ltd., Edinburgh and London, p. 80, 1953.

16. Clark, W. E. Le Gros, and Meyer, M. : Brit. med. bull. 6 : $341,1950$.

17. Niimi, K.: Saishin Igaku 8: 8, 1953 (In Japanese).

18. Droogleever Fortuyn, J. et al.: Recent Neurological Research, edited by Biemond, A., Elsevier Publishing Company, Amsterdam, p. 46, 1959. 